\title{
Public housing redevelopment: impacts on neighbourhood quality and residents' economic stability and social capital
}

\author{
A. M. Curley \\ OTB Research Institute, Delft University of Technology, The Netherlands
}

\begin{abstract}
Efforts to redevelop urban neighbourhoods suffering from severe concentrations of poor people and minorities have been underway in many US and European cities for over a decade. HOPE VI is one initiative that is redeveloping US public housing projects into new mixed-income communities. It is thought that the combination of relocation and redevelopment will lead to improvements in poor people's lives. This paper contributes evidence from a longitudinal study that followed residents from one HOPE VI site over four years during which they were relocated out of (and sometimes back into) their original community. Analyses of multiple waves of surveys and in-depth interviews with residents, along with Census and administrative data, revealed the effects of relocation on neighbourhood quality, economic stability, and social capital. Overall, relocation to private market housing with portable vouchers and relocation back into the new mixed-income community led to dramatic improvements in neighbourhood quality for many residents but decreased economic stability for many. In contrast, those who relocated to other public housing neighbourhoods made no gains in neighbourhood quality, but they did not suffer in terms of economic stability. As for social capital, most residents had very little interaction with their new neighbours, and relocation to mixed neighbourhoods did not lead to the formation of better job networks. The findings suggest that redevelopment initiatives like HOPE VI can impart major changes in poor people's lives, but these changes are not as uniform or predictive as policymakers might expect.
\end{abstract}

Keywords: public housing, urban poverty, neighbourhood quality, urban redevelopment, HOPE VI, relocation, economic stability, social capital. 


\section{Introduction}

Urban neighbourhoods with severe concentrations of poor people and minorities have been targeted for redevelopment in many US and European cities for over a decade. HOPE VI, which stands for Housing Opportunities for People Everywhere, is one initiative aimed at redeveloping US public housing projects into new mixed-income communities. As communities are reconstructed, households relocate to other neighbourhoods - either to private market housing with vouchers or to other housing developments. This paper examines how residents' lives were impacted by relocation and changes in neighbourhood, and whether certain groups of residents fared better in terms of neighbourhood quality, economic stability, and social capital. Analyses of administrative and Census data, along with multiple waves of surveys and in-depth interviews with residents revealed the effects of the program on residents from one site.

\section{The HOPE VI program}

In 1993 the HOPE VI program was created with the goal of redeveloping the "most severely distressed" public housing projects throughout the country. These include developments that suffer not only from physical deterioration, but also from isolation, inadequate services, crime, chronic unemployment, welfare dependency, and high concentrations of minorities, extremely poor residents, and single parent families. By reducing the density of the developments, building housing that blends in with the surrounding community, creating streets that connect the developments to the abutting areas, bringing in higher income residents, and providing supportive social services, the HOPE VI program seeks to transform blighted areas of concentrated poverty into new mixed-income communities of opportunity.

While the physical transformation of these communities is the most obvious effect of the program, HOPE VI is intended to have additional positive effects on residents. Another goal of the program is to improve the life chances of lowincome families by providing them quality housing in decent neighbourhoods where they can live among people who are better connected to mainstream society (i.e. people who are steadily employed). Living in isolated communities of concentrated poverty is recognized as having detrimental effects on residents' lives. A large number of studies assessing "neighbourhood effects" support this, as they document the relationship (though not usually the causal link) between neighbourhood poverty and a host of negative individual outcomes, even when controlling for individual and family characteristics. William Julius Wilson [1] argued that poor urban neighbourhoods leave residents devastatingly isolated and disconnected from mainstream society. Isolating residents from middle-class people and working role models, poverty-concentrated communities limit poor people's access to important job networks and mainstream norms pertaining to work, family, and community [1, 2]. In essence, residents of such communities are thought to be deficient in social capital, which has been defined as "the connections among individuals_-social networks and the norms of reciprocity 
and trustworthiness that arise from them" [3]. Living in a poverty-concentrated neighbourhood is thought to limit social networks since the people residents are likely to meet and interact with are most likely disadvantaged like themselves. Some studies have suggested that having diverse social networks that include ties to people of different socioeconomic status and ethnicity can be important for accessing information and resources to get ahead [1]. With the creation of mixed-income housing and dispersal of poor residents into other communities, it is assumed that HOPE VI will improve the social capital (i.e. job networks) of the poor by improving their proximity to higher income and working people. These benefits, however, depend on social interaction between different types of people. This paper explores the following questions:

- Can public housing redevelopment, through the creation of mixedincome communities or through the relocation of residents to other neighbourhoods lead to improvements in neighbourhood quality?

- Do such initiatives positively impact residents' economic stability?

- Do such initiatives positively impact residents' social capital?

\section{The study}

A multi-method approach was used to assess the effects of HOPE VI at one site in Boston, Massachusetts. Four key data sources were used in this longitudinal case study of the Maverick Garden's HOPE VI program. First, administrative data from the housing authority were used to track the addresses to which families were relocated. Then addresses were matched to US Census data to examine the characteristics of new neighbourhoods. Then we utilized the longitudinal resident survey data, which was conducted in three waves: 1. the Baseline/pre-HOPE VI survey, 2003, $(n=216)$; 2. the Interim follow-up survey, 2004, $(n=125)$; and 3. the Final post-HOPE VI survey, 2007, $(\mathrm{N}=199)$. Ninetysix final surveys were completed in Spanish (48\%), 94 in English (47\%), and 9 in Vietnamese (5\%). Overall, the final survey sample is comparable to the larger population of original Maverick tenants in terms of race and the main relocation outcomes. We use the survey data to assess pre and post-HOPE VI outcomes, as well as to compare outcomes across the four main post-HOPE VI relocation groups (Maverick Landing, public housing, Section 8, and homeownership). Lastly, repeated in-depth interviews with 30 women from the original community provide rich data that helps us understand some of the processes through which urban redevelopment affected residents' lives.

\section{The findings}

The Maverick HOPE VI program was implemented in phases over a five year period, and involved the demolition of 413 units and the rebuilding of 396 units (both on and off-site), 305 of which are affordable. During the redevelopment, residents could relocate to other public housing developments in the city, take portable Section 8 vouchers, relocate on-site (into vacant units slated for demolition in a later phase), purchase a home, or leave subsidized housing 
altogether. Section 8 is a subsidized portable voucher program that enables residents to rent units in the private market rather than live in a public housing project reserved for low-income people only. As the phases of the new development were completed, residents were screened and relocation staff assigned the new units at the renamed Maverick Landing based on household eligibility, size, and lottery number. Because the new community included fewer subsidized units than the original site, it was inevitable that not all residents would return to the rebuilt neighbourhood. When the Maverick HOPE VI program was completed and all new units were occupied (late 2006), just under half of the original 375 households (48\%) returned to Maverick Landing, while others remained permanently off-site in other public housing developments $(23 \%)$, with portable Section 8 vouchers $(17 \%)$, in market rate housing $(3 \%)$, or in homes they purchased (2\%). Another $6 \%$ were evicted or abandoned their units and were no longer being tracked by the housing authority.

\subsection{Neighbourhood quality}

Residents' addresses were matched to US Census tracts to assess whether the HOPE VI program was successful in deconcentrating neighbourhood poverty and racial segregation for the original Maverick residents. The US Census is a decennial survey of households, organized by "tracts," which typically coincide with neighbourhood, administrative, or natural boundaries.

According to the 2000 Census, the Maverick neighbourhood had a poverty level of $43 \%$ and included $50 \%$ non-white residents, indicating that Maverick was a very poor and segregated community. Until the 2010 census data is available, we can only compare the neighbourhood poverty and segregation levels of the pre-HOPE VI Maverick community to that of relocatees' new neighbourhoods.

Table 1: $\quad$ Poverty and segregation levels of relocatees' new neighbourhoods.

\begin{tabular}{|l|c|c|c|c|c|}
\hline & Maverick & $\begin{array}{c}\text { Public } \\
\text { Housing } \\
(\mathrm{n}=181)\end{array}$ & $\begin{array}{c}\text { Sec. 8 } \\
(\mathrm{n}=65)\end{array}$ & $\begin{array}{c}\text { Market } \\
\text { Rate } \\
(\mathrm{N}=12)\end{array}$ & $\begin{array}{c}\text { Home- } \\
\text { owner } \\
(\mathrm{n}=8)\end{array}$ \\
\hline $\begin{array}{l}\text { Neighbourhood } \\
\text { poverty level* }\end{array}$ & $43 \%$ & $31 \%$ & $14 \%$ & $22 \%$ & $12 \%$ \\
\hline $\begin{array}{l}\text { Percent } \\
\text { non-white* }\end{array}$ & $50 \%$ & $42 \%$ & $35 \%$ & $55 \%$ & $35 \%$ \\
\hline
\end{tabular}

${ }^{*} \mathrm{p}<.001$ (Note that addresses were not available for the 24 households that were evicted or abandoned their units.)

Findings indicate that the Maverick HOPE VI relocation brought many residents to neighbourhoods that were considerably different economically and racially than Maverick Gardens. There are statistically significant differences in poverty and segregation levels across the relocation groups. Most notable is that Section 8 and homeownership brought residents to substantially lower-poverty neighbourhoods (14\% and $12 \%$ respectively), whereas moves to public housing and market-rate housing brought residents to areas that were only slightly less 
poor than Maverick (31\% and 22\% vs. 43\%). While all original Maverick households lived in an extreme poverty neighbourhood (above $40 \%$ poor) prior to HOPE VI, after HOPE VI only $3 \%$ of Section 8 movers lived in such high poverty census tracts. The gains Maverick voucher holders made in moving to lower poverty areas are even greater than those made by voucher users from other HOPE VI sites: $73 \%$ of Maverick voucher holders moved to neighbourhoods with poverty rates below 20 percent, compared to $47 \%$ of residents in the five-site HOPE VI Panel Study [4]. While Census data indicate that portable vouchers were an effective means in moving Maverick residents out of concentrated poverty, relocating families to other public housing projects was much less effective, as $40 \%$ of public housing movers ended up in other extreme poverty census tracts. This finding is consistent with the HOPE VI Panel Study, which similarly found that a large share of public housing movers $(34 \%)$ relocated to other extreme poverty neighbourhoods [4].

Although HOPE VI moved many residents to lower poverty communities, most relocatees continued to live in racially segregated areas. Public housing movers lived in areas averaging 42\% minority, compared to Maverick (50\%) and Section $8(35 \%)$. These findings are also consistent with other studies, which similarly find that the majority of relocated HOPE VI residents continue to live in highly segregated communities [4].

While the Census data are useful in providing statistics on the general areas in which residents now live, other measures were needed to adequately assess the quality of such places. One limitation of Census data is that the tracts in which neighbourhood statistics are measured do not necessarily capture the spatial areas residents consider to be their 'neighbourhood' or the areas of influence in their lives. Thus, we turn to the resident survey to understand how residents themselves experience their new communities and consider whether their experiences coincide with the picture offered by the "official" Census statistics.

To get a better sense of neighbourhood conditions in terms of safety, the resident survey inquired about specific neighbourhood problems both pre and post-HOPE VI, including shootings, people being attacked/robbed, rape/sexual attacks, people selling and using drugs, gangs, groups of people just hanging out, police not coming when called, graffiti, lack of outside lighting, trash in parking lots, sidewalks, and lawns, unattractive common outdoor areas, and lack of recreational space. Using a neighbourhood problem index based on the average score per respondent for these 13 issues (Cronbach's $\alpha=.96$ ), we found a statistically significant decrease in the reporting of such problems post-HOPE VI. Scores ranged from a low of zero (no problems) to a high of 1 (all 13 problems). Neighbourhood problem scores were cut nearly in half, from an average of .41 prior to HOPE VI to .23 after HOPE VI $(\mathrm{N}=128)$. Yet, these scores varied significantly by relocation group in the post-HOPE VI survey, with Maverick Landing scoring the lowest (.13), followed by Section 8 (.20), homeowners (.41), and public housing residents $(.59)(\mathrm{F}=25.33, \mathrm{p}<000)$.

Maverick Landing residents' comments during the surveys and in-depth interviews revealed that these improvements in neighbourhood living conditions and safety were very meaningful and contributed to the impression that their 
quality of life had improved. For example, a typical comment about improvements in safety included the following made by a Maverick Landing resident:

Before I lived in the old projects - there was fighting, shooting, a lot of crime. Now it's peaceful, now I can sit outside, I have a beautiful backyard with a view. My family is safe. It's a good place to be.

Similar to Maverick Landing movers, Section 8 residents also recognized improvements in safety as one of the most important impacts HOPE VI and the voucher had on their families. Many talked about what the safety improvements meant for their children in particular. One single mother said if she hadn't moved with Section 8, "...my children would have been in gangs."

In contrast to the safety benefits Section 8 and Maverick Landing residents experienced, the majority of residents who relocated to other public housing developments continued to live in areas of high crime and social dysfunction. It is quite astonishing that public housing respondents reported more neighbourhood problems on average than baseline residents. As one resident reflected, "It [HOPE VI] ended up relocating us to a project even worse than Maverick Gardens."

\subsection{Economic stability}

Now that we have an understanding of the program impacts on neighbourhood quality, we turn to the issue of economic stability. Key measures of economic stability included income, food and utility hardships, and changes in financial situation over time. While fluctuations in economic stability may be common and perhaps expected among a low-income population, we delineate when residents experienced changes they attributed to relocation and when differences in economic stability existed across relocation groups.

The majority of survey respondents had very low incomes, with two-thirds earning less than $\$ 15,500$ per year. Of the matched sample reporting income both pre and post-HOPE VI, about one quarter experienced a movement in or out of their baseline income bracket. For example, 28\% of those in the lowest income bracket $(\$ 15,500$ or less) pre-HOPE VI climbed above this threshold by the final survey; and $22 \%$ of those in the higher bracket at baseline dropped down to the lower bracket at the final survey. In addition to fluctuations in income over time, there were statistically significant differences in income levels across the relocation groups in the post-HOPE VI survey. Perhaps not surprising, all homeowners earned above the low threshold of $\$ 15,500$, compared to nearly half of the Section 8 respondents $(43 \%)$, and roughly one quarter each of Maverick Landing and public housing movers.

To gain a better understanding of residents' economic stability, we asked questions about utility shut-offs, their ability to secure enough food for their households, and changes in their financial situation over time. The results were somewhat surprising. Although Section 8 movers and homeowners had higher incomes on average, they suffered more financial hardships than other movers (see Table 2). One quarter of the homeowners and 15\% of Section 8 movers reported their gas or electric service had been shut off in the past year due to 
Table 2: $\quad$ Measures of economic stability.

\begin{tabular}{|l|c|c|c|c|}
\hline In the last year... & $\begin{array}{c}\text { Maverick } \\
\text { Landing } \\
(\mathrm{N}=105)\end{array}$ & $\begin{array}{c}\text { Section } \\
8 \\
(\mathrm{~N}=41)\end{array}$ & $\begin{array}{c}\text { Public } \\
\text { Housing } \\
(\mathrm{N}=40)\end{array}$ & $\begin{array}{c}\text { Home- } \\
\text { owner } \\
(\mathrm{N}=8)\end{array}$ \\
\hline $\begin{array}{l}\text { Was your gas or electric service shut } \\
\text { off?* }\end{array}$ & $4 \%$ & $15 \%$ & $3 \%$ & $25 \%$ \\
\hline $\begin{array}{l}\text { Was your telephone service shut } \\
\text { off?* }\end{array}$ & $9 \%$ & $27 \%$ & $10 \%$ & $13 \%$ \\
\hline $\begin{array}{l}\text { Did you have trouble getting enough } \\
\text { food for your household?** }\end{array}$ & $14 \%$ & $22 \%$ & $3 \%$ & $25 \%$ \\
\hline
\end{tabular}

*Differences across groups are statistically significant at the $\mathrm{p}<.05$ level.

** Borderline significance at $\mathrm{p}<.06$.

non-payment. Further, $27 \%$ of Section 8 and 13\% of homeowners had their telephones disconnected, compared to $9 \%$ of Maverick Landing and 10\% of public housing movers. Food hardships were also greater among Section 8 residents $(22 \%)$ and homeowners (25\%) than Maverick Landing (14\%) and public housing residents $(3 \%)$.

Despite their lower incomes, Maverick Landing and public housing residents were less likely to suffer food and utility hardships, suggesting that these forms of housing subsidy may provide for more financial stability. Public housing residents, for example, pay a set price for rent (depending on their income) and this price includes utilities. Maverick Landing respondents are responsible for paying for their own electricity (but not their gas, which is the primary source for heat). In contrast, Section 8 voucher holders must pay for their own utilities, and although they are provided a utility allowance, it does not always cover the actual costs of heat and electricity. Thus, Section 8 respondents and homeowners are more likely to suffer the consequences of unexpected increases in housing and utility costs. The increased financial hardships voucher holders in this study experienced is consistent with other HOPE VI findings [5, 6].

When asked how their financial situation compared to their situation five years ago when they were living at the old Maverick Gardens (prior to HOPE VI), about half the respondents said they experienced no changes, $31 \%$ indicated their financial situation had declined and 19\% indicated their situation had improved. As with other measures of economic stability, there were significant differences across the relocation groups, with Section 8 and homeowners more likely to report a decline in their financial situation over the HOPE VI period (44\% and 50\% respectively), compared to Maverick Landing and public housing movers $(26 \%$ and $21 \%)$.

When residents were asked what contributed to the change in their financial situation, several common reasons, some relating to relocation, emerged. For those who experienced a decline over the HOPE VI period, nearly half $(45 \%)$ specified their new utility bills as the sole cause. Again, Section 8, homeowners, and to a lesser degree Maverick residents, bore the brunt of financial setbacks due to relocation out of traditional public housing. Others cited factors such as an increase in living costs with no corresponding increase in income $(23 \%)$ and a change in job or losing one's job (23\%). 
Of the $20 \%$ who indicated their financial situation improved over time, over half $(52 \%)$ said the fact that they went from being unemployed or on welfare to being employed or that they got a new better-paying job during this time contributed to the improvement. Other reasons included being better at "stretching the money" as well as eliminating "draining" ties to people from the old community. For example, one resident said "I used to be very generous at the old Maverick." Moving away helped her realize that she can conserve more resources for her family by not being so generous, and this is easier now since the people around her are "less needy."

The findings from this study thus far tell us that the HOPE VI program can impart changes in people's lives by moving them to safer, more orderly communities or to more dangerous communities; and that differential effects of relocation on residents' economic stability are often a function of their housing type. Ironically, some of those who experienced the greatest improvements in housing and neighbourhood quality experienced the greatest financial hardships associated with their new housing situations. But what about the expected social impacts of HOPE VI? Next, we explore program impacts on residents' social capital.

\subsection{Social capital}

Now that we have a better picture of residents' neighbourhood conditions and economic stability, we turn to social capital, looking specifically at social ties with new neighbours. One goal of creating mixed-income housing was to improve the integration of lower-income residents into mainstream society by improving their social networks. The expectation was that low-income people in economically mixed neighbourhoods would interact and benefit from having higher income neighbours who are more likely to be educated and steadily employed. As stated earlier, this assumption was based on established theories of poverty that hold that people in poverty-concentrated neighbourhoods remain poor in part because they are isolated from important job networks since they are likely to only come into contact with other low-income, severely disadvantaged people $[1,2]$. Thus, we were interested in whether and how Maverick residents connected with and benefited from their new neighbours.

Two important factors must be considered when assessing local social networks: actual and expected length of residence in the community. Length of residence at the time of the final survey did vary by relocation group, with Maverick Landing residents averaging 2.0 years in their current unit, public housing 3.3 years, Section 8 averaging 2.3 years, and homeowners 1.4 years. Maverick Landing residents appear to be the most rooted, with $77 \%$ planning to remain in the community for a long time. There was a certain degree of uncertainty about future housing among others in the sample, with $56 \%$ of Section 8 movers and $40 \%$ of public housing movers reporting they are uncertain about how long they will stay in their current locations.

To get a better sense of the social climate and residents' interactions with their neighbours we asked them how well they know their neighbours and whether they socialize, trust, and help one another. In general, most respondents 
reported not knowing their neighbours very well, not socializing with them, and more often than not, that their neighbours tend to go their own way rather than help each other out. Based on the greater amount of time spent in their current environments, we might expect public housing and Maverick Landing respondents to be better connected in their neighbourhoods (although Maverick Landing residents had less time in their current units, they had lived at Maverick an average of 14 years pre-HOPE VI). Yet it was homeowners who were most likely to report their neighbours help one another rather than "go their own way" (43\%), compared to $33 \%$ of Section $8,32 \%$ of Maverick Landing, and $21 \%$ of public housing movers.

In order to assess the extent of socializing among old and new residents in the mixed-income community, we asked Maverick Landing respondents about their engagement with new residents. The majority $(68 \%)$ reported having no interaction at all with new residents, while 14\% said "hello" to neighbours, and $18 \%$ occasionally conversed beyond "hello". It appears that while many residents may exchange greetings or receive a nod of recognition from newer residents, there is very little social mixing among the old lower-income residents and new higher-income residents in the new mixed-income community. This finding is not unique, as others have similarly reported low levels of social interaction among neighbours in mixed-income communities [5, 6]. Yet, most Maverick Landing respondents had positive or neutral things to say about their new neighbours $(86 \%)$, leaving open the possibility that interaction may develop over time.

Finally, we asked residents specifically about their job networks to assess whether their new neighbours were proving to be useful job contacts for them. Most found their jobs through friends and relatives, but this ranged from a low of $45 \%$ among Maverick Landing residents to a high of $77 \%$ among public housing respondents. Contrary to policy expectations, none of the employed respondents found their job through a neighbour - not even those who moved to more economically mixed communities. Kleit [7] similarly found that HOPE VI relocatees continued to use their close social contacts for job leads rather than their new neighbours. These finding suggests that some of the assumptions about poor people's social networks, how they find jobs, and how they benefit from their neighbours may be misguided.

\section{Conclusion}

The Maverick HOPE VI program clearly improved the living conditions of residents who relocated back to Maverick Landing and for many of those who moved to other neighbourhoods with vouchers or by purchasing homes. Unfortunately, the residents who were relocated to other public housing developments appear to be the real losers of the Maverick HOPE VI program in terms of neighbourhood conditions. This group comprises a substantial minority $(23 \%)$ of residents, and having few alternative options for housing, these families are likely to endure the negative long-term effects of living in dangerous and intolerable environments. Relocating HOPE VI families to other distressed 
public housing developments contradicts the goals of the program itself, including improving living conditions and decreasing poverty concentration. The program should reduce the potential for negative neighbourhood effects by ensuring that families are not relocated to such communities.

Ironically, although relocation brought many households to better quality neighbourhoods, these new housing arrangements came with a cost. Paying for utility bills in addition to rent and other living expenses had a negative impact on some families' economic stability simply by reducing their financial capacity to make ends meet. Expanding financial support to help households cope with the increased and fluctuating utility costs may help maximize the potential for positive neighbourhood effects. Lastly, the intended social integration effects of the program did not materialize in the form of meaningful social interactions with neighbours or expanded job networks via new neighbours. In conclusion, the main improvement HOPE VI brought to residents in this study was in safety and neighbourhood conditions, not economic stability or social capital. And the key setbacks residents experienced due to HOPE VI were in neighbourhood conditions for public housing movers and economic stability for voucher users and homeowners. Urban redevelopment programs targeting povertyconcentrated neighbourhoods must consider the potential for both improvements and setbacks families may experience and take caution to reduce costs associated with the portable voucher and homeownership housing options.

\section{References}

[1] Wilson, W.J., The Truly Disadvantaged, The University of Chicago Press: Chicago. 1987.

[2] Briggs, X. Brown kids in white suburbs: Housing mobility and the many faces of social capital, Housing Policy Debate, 9(1): pp. 177-213, 1998.

[3] Putnam, R. Bowling alone, Simon \& Schuster: New York, pp.19, 2000.

[4] Buron, L., Levy, D.K. \& Gallagher, M. Housing choice vouchers: How HOPE VI families fared in the private market, Urban Institute: Washington, D.C., 2007.

[5] Buron, L., Popkin, S.J., Levy, D., Harris, L.E., \& Khadduri, J. The HOPE VI resident tracking study, Urban Institute: Washington, D.C., 2002.

[6] Kleit, R.G., Reder, S., \& Abramo, A. HOPE VI for High Point interim report: Panel study baseline and initial relocation outcomes, Daniel J. Evans School of Public Affairs: University of Washington, 2004.

[7] Kleit, R.G., The role of neighbourhood social networks in scattered-site public housing residents' search for jobs. Housing Policy Debate, 12(3): pp. 541-573, 2001. 